\title{
Assessment of the effect of angiotensin- converting enzyme inhibitors and angiotensin receptor blockers in peritoneal dialysis patients: a systematic review and meta-analysis on clinical trials
}

\author{
Minoru Ito ${ }^{1,2^{*}}$, Yosuke Saka ${ }^{1,3}$, Yusuke Kuroki $^{1,4}$, Kaoru Yasuda ${ }^{1,5}$, Hiraku Tsujimoto ${ }^{1}$, Yasushi Tsujimoto ${ }^{1}$,
} Hidemichi Yuasa ${ }^{1}$, Munekazu Ryuzaki ${ }^{1}$, Yasuhiko Ito ${ }^{1}$ and Hidetomo Nakamoto'

\begin{abstract}
Background: Renin-angiotensin system inhibitors (RASIs), either angiotensin-converting enzyme inhibitors or angiotensin receptor blockers, are widely used in patients with non-dialysis chronic kidney disease, as a reninangiotensin system (RAS) blockade has renoprotective effects. Several studies show that preserving residual renal function is important for a better prognosis in peritoneal dialysis (PD) patients. Here, we systematically reviewed the beneficial or harmful effects of RAS blockade in PD patients.

Methods: PubMed, the Cochrane Library, Embase, the Ichushi web databases, and other resources were selected to search clinical guidelines, systematic reviews, and randomized controlled trials (RCT) published before April 14, 2017, using "peritoneal dialysis," "angiotensin-converting enzyme inhibitors," "angiotensin II type 1 receptor blockers," and "randomized controlled trial" as keywords. Desired results were total mortality, technical survival, urine volume, residual renal function calculated by glomerular filtration rate (GFR), cardiovascular events, and anuria progression rate. The study protocol is registered in PROSPERO (International Prospective Register of Systematic Reviews) under the registration number CRD42018104106.

Results: Of a total of 339 studies, eight were identified as suitable for the analysis. Only one study was blinded, whereas the other seven studies were open-label. RASI appeared to preserve residual renal function, GFR (4 studies, 163 participants, mean difference [MD] $0.97 \mathrm{~mL} / \mathrm{min} / 1.73 \mathrm{~m}^{2}$, 95\% confidence interval [Cl] 0.49-1.44), and urine volume (6 studies, 194 participants, MD $142.56 \mathrm{~mL}$ 95\% Cl 25.42-259.69), although there were no beneficial effects of RASI on total mortality, technical survival, cardiovascular events, and anuria rate.
\end{abstract}

Conclusions: Our analysis found that RASIs contribute to preserving GFR and urine volume in PD patients. As the number of study participants is small, further studies with a larger sample size are required.

Keywords: Peritoneal dialysis, Renin-angiotensin system inhibitors, Residual renal function, Systematic review

\footnotetext{
* Correspondence: miito@seieig.or.jp

'Working Group on Revision of Peritoneal Dialysis Guidelines, Japanese

Society of Dialysis Therapy, Tokyo, Japan

2Department of Nephrology and Dialysis Center, Yabuki Hospital, 4-5-5

Shima-Kita, Yamagata 990-2464, Japan

Full list of author information is available at the end of the article
}

(c) The Author(s). 2019 Open Access This article is distributed under the terms of the Creative Commons Attribution 4.0 International License (http://creativecommons.org/licenses/by/4.0/), which permits unrestricted use, distribution, and reproduction in any medium, provided you give appropriate credit to the original author(s) and the source, provide a link to the Creative Commons license, and indicate if changes were made. The Creative Commons Public Domain Dedication waiver (http://creativecommons.org/publicdomain/zero/1.0/) applies to the data made available in this article, unless otherwise stated. 


\section{Background}

Residual renal function (RRF) is recognized as a significant factor in improving the prognosis of patients undergoing peritoneal dialysis (PD). Preserving RRF contributes to achieving adequate dialysis targets and improving fluid status. A reanalysis report of the Canada-USA (CANUSA) Peritoneal Dialysis Study Group study showed that an increment in urine volume or preserved glomerular filtration rate (GFR) is associated with better chances of survival [1]. Furthermore, several past studies have reported the benefits of preserving RRF in PD patients [2-6]. For these reasons, a renoprotective strategy is crucial for improving the mortality and technical survival of PD patients.

Renin-angiotensin system inhibitors (RASIs), angiotensinconverting enzyme inhibitors (ACEIs) or angiotensin receptor blockers (ARBs), have renoprotective and mortalityreducing effects in chronic kidney disease (CKD) patients [7, 8]. These drugs are generally used as first-line therapy for CKD patients with hypertension. The clinical practice guideline of the Japanese Society of Nephrology also recommends RASIs for CKD patients [9]. In view of these facts, the clinical question arose as to whether RASIs preserve the RRF of PD patients. Several clinical studies were performed to estimate the effect of RASIs on RRF of PD patients [10-22], including both randomized controlled trials (RCTs) and non-RCTs, with conflicting results.

This study intended to evaluate the beneficial or harmful effects of RASIs as well as the effect of preserving RRF in patients receiving PD. We systematically reviewed relevant RCTs investigating the effect of RASIs on residual renal function in PD patients. We also examined the differences in impact of ACEIs and ARBs.

\section{Methods}

The study is presented following Preferred Reporting Items for Systematic Review and Meta-Analyses (PRISMA) guidelines [23]. The protocol for the systematic review (SR) and meta-analysis was registered with the International Prospective Register of Systematic Reviews (PROSPERO), registration ID CRD42018104106.

\section{Study selection and data management}

Initially, with the help of an expert librarian, we searched article records included in previously reported SRs and clinical practice guidelines (CPGs) dealing with the effects of RASIs in PD from 1 January 1988 to 10 April 2017. The searched databases were PubMed, Cochrane Library, Embase, Ichushi web, and other resources. After the search for optimal SRs and CPGs, we identified the articles included in the SRs and CPGs.

We then electronically screened the same databases to identify any articles missed by the initial search (1 January 1988 to 10 April 2017). The keywords for database screening were "peritoneal dialysis," "angiotensin-converting enzyme inhibitors," "angiotensin type II receptor blockers," and "randomized controlled trial." The full strategy is described in Additional file 1 . In the case of articles where the required data were not available, we contacted the authors by email.

Four reviewers (MI, YS, YK, and KY) independently screened all the titles and abstracts according to a priori selection criteria. Subsequently, the same reviewers assessed the eligibility of the full texts of all the potentially suitable articles.

\section{Inclusion and exclusion criteria}

We included completed RCTs that assessed the effects of RASIs in patients undergoing PD. Our primary outcome was the RRF (change of urine volume or GFR). Other outcomes of interest were all-cause mortality, technical survival, anuria rate, and cardiovascular events.

The comparison patterns were as follows:

1. ACEI or $\mathrm{ARB}+$ other drugs versus placebo + other drugs

2. ACEI or $A R B+$ other drugs versus other drugs

3. ACEI + other drugs versus $\mathrm{ARB}+$ other drugs.

We also included trials with adult ( $>18$ years old) endstage kidney disease (ESKD) patients undergoing PD without restrictions on age, sex, or ESKD as a primary disease.

We excluded studies involving participants with acute kidney injuries, receiving hemodialysis (HD) or PD/HD combined therapy and anuria.

\section{Data extraction}

Data extraction was carried out independently by the four review authors (MI, YS, YK, and KY) using standardized methods. Where a comparison of more than two interventional drugs or control drugs existed in a study, the reports were handled as separate studies in one analysis. Studies not written in English were translated before assessment.

\section{Risk of bias assessment}

The four review authors (MI, YS, YK, and KY) independently assessed the risk of bias in included studies using the risk of bias tool in the Cochrane handbook [24].

We assessed the random sequence generation, allocation concealment, blinding, incomplete outcome data, selective reporting, and others. Risks in each domain were assessed in the following three categories: high risk, low risk, and unclear. Any discrepancy was identified and resolved through discussion (with a third author where necessary).

\section{Data synthesis and statistical methods}

We conducted the analysis comparing the effects of RASIs and other drugs as "SR1.1." regarding ACEIs and 
ARBs together as RASIs although ACEIs and ARBs have different mechanisms of action. The market share of ARBs is larger than ACEIs in Japan, suggesting that a separate comparison of the effects of ARBs and ACEIs against other drugs does not reflect reality. Additionally, we conducted a comparison of the independent effects of ACEIs and ARBs as "SR1.2." to address the question of whether either is more favorable for PD patients.

The results were analyzed using Review Manager (RevMan), Version 5.3 software (The Cochrane Collaboration, Oxford, UK). Dichotomous outcome results with a low event rate were expressed as risk difference (RD) with 95\% confidence intervals (CI). Where a significant number of events occurred, the risk ratio (RR) was used for analysis. For continuous scale outcomes (residual renal function and urine volume), results were expressed as the mean difference (MD). Heterogeneity across the included studies was assessed statistically by calculating the overall $I^{2}$ values. Data were pooled using the random-effect model.

\section{Results}

\section{Results of search}

The previous SR and CPG search yielded two SRs [25, 26] which contained four $[10,11,15,27]$ and six [10, $15-18,20]$ RCTs in each, with two $[10,15]$ duplicated. We thus identified eight articles from this step. Through a new database search, 329 titles and abstracts were identified, of which, three articles $[11,19,22]$ were potentially eligible. We carried out full-text article assessments of 11 studies and excluded three for the following reasons: duplication [11], inconsistent outcomes [27], and a too short observational period [22]. Finally, eight trials were entered into this review. Figure 1 shows the details of the study selection process.

The eight RCTs included in the analysis are summarized in Table 1. One study assessed the efficacies of ACEIs [10]. Two studies compared the effects of ACEIs and ARBs with a cross-over RCT [16], and a parallel RCT [20]. The remaining five studies assessed the effects of ARB [11, $15,17-19]$, where one study conducted two intervention groups using different ARBs [19].

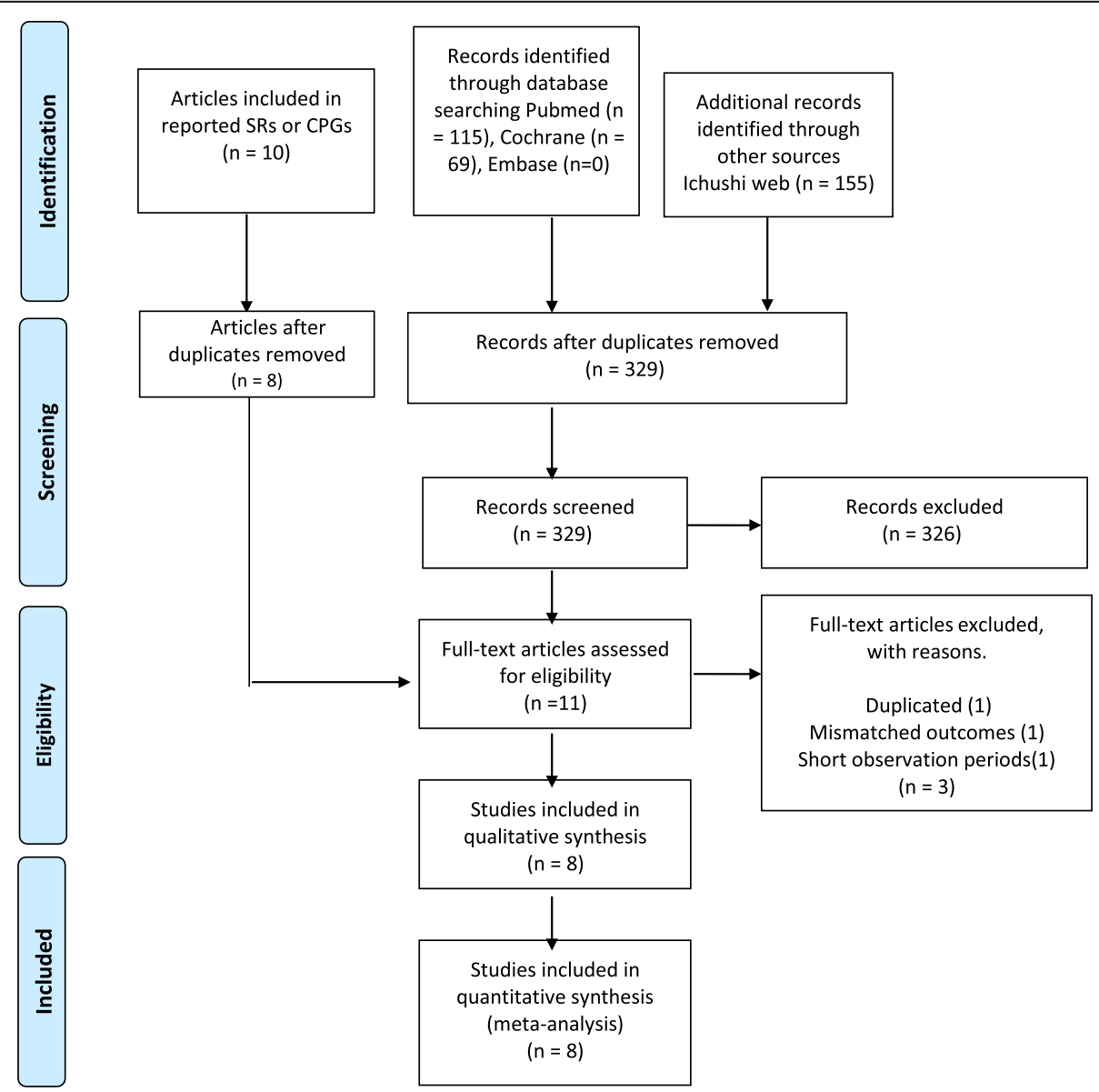

Fig. 1 PRISMA flow diagram showing a selection of randomized controlled trials 


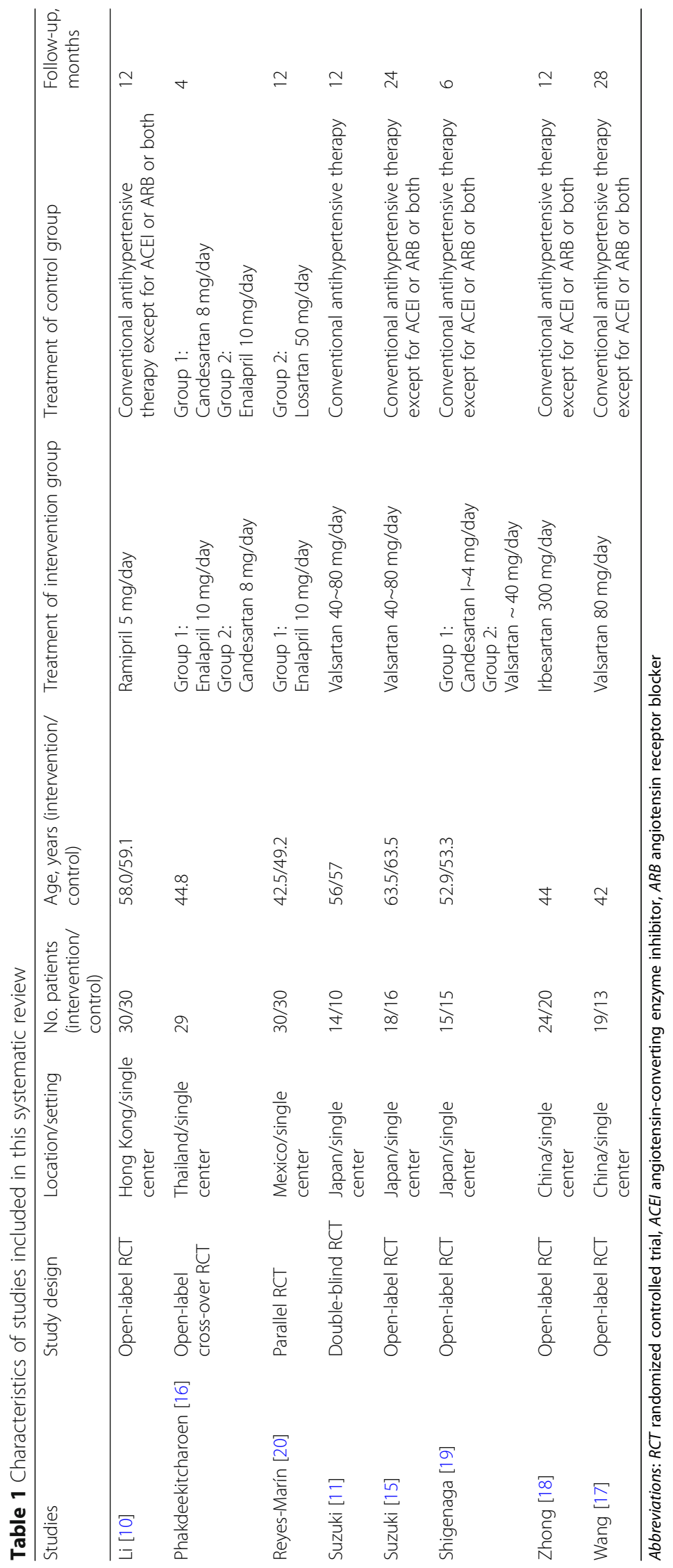




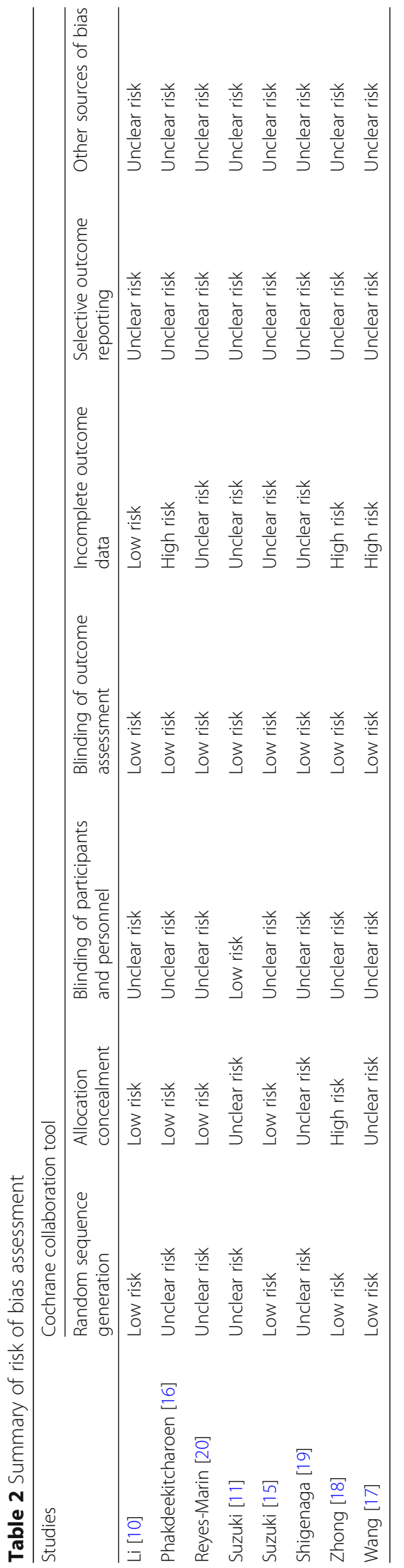


Risk of bias in included studies

Table 2 summarizes the details of our assessment of the risk of bias among the included studies. Four studies used computer-generated lists for randomization $[10,15,17,18]$. Two of these had not detailed the randomization method [17, 18], but the authors of a previous SR confirmed that these studies also used the computergenerated methods [26]. One study provided no information on allocation concealment [18]. Three studies had incomplete outcome data [16-18]. Most of our primary outcomes analyzed in the review were obtained from objective data, and not influenced by the blinding of patients and investigators.

\section{Effects of interventions}

The summaries of the findings for all the outcomes in SR1.1. and SR1.2. are summarized in Additional files 2 and 3, respectively. SR1.1. is a comparison of RASIs including ARBs or ACEIs versus conventional therapy for preserving RRF in PD patients. SR1.2. is a comparison of ARBs versus ACEIs for preserving RRF in PD patients.

\section{Residual renal function (GFR)}

SR1.1.

Four studies (ARB, 3; ACEI, 1) reported the effects of RASIs versus other antihypertensive drugs on RRF after follow-up periods of over 12 months. The comparison of RASIs and other drugs indicated a small but significant benefit in preserving RRF (mean difference [MD] 0.97 $\mathrm{mL} / \mathrm{min} / 1.73 \mathrm{~m}^{2}, 95 \%$ confidence interval [CI] 0.49-1.44, $\left.I^{2}=79 \%\right)$, suggesting that RASIs have renoprotective effects compared to other antihypertensive drugs (Fig. 2). However, significant heterogeneity was identified. In subgroup analysis, ARBs significantly reduced the decline of RRF (MD $1.11 \mathrm{~mL} / \mathrm{min} / 1.73 \mathrm{~m}^{2}, 95 \%$ CI 0.38 $1.83, I^{2}=76 \%$ ), and ACEIs also preserved RRF (MD $0.72 \mathrm{~mL} / \mathrm{min} / 1.73 \mathrm{~m}^{2}, 95 \%$ CI $0.54-0.90$ ) compared to other antihypertensive drugs. There was significant heterogeneity for the effects of ARBs.

\section{SR1.2.}

One study found no significant differences in RRF preservation between ARBs and ACEIs over 12 months (MD $0.18 \mathrm{~mL} / \mathrm{min} / 1.73 \mathrm{~m}^{2}, 95 \% \mathrm{CI}-0.04$ to 0.40 ) (Fig. 2).

SR1.1.

\begin{tabular}{|c|c|c|c|c|c|c|c|c|c|c|}
\hline \multirow{3}{*}{$\frac{\text { Study or Subgroup }}{1.1 .1 \text { ARB }}$} & \multicolumn{3}{|c|}{ ARB or ACEI } & \multicolumn{3}{|c|}{ Other Drugs } & \multirow{2}{*}{ Weight } & \multirow{2}{*}{$\begin{array}{l}\text { Mean Difference } \\
\text { IV, Random, } 95 \% \mathrm{Cl}\end{array}$} & \multirow{2}{*}{\multicolumn{2}{|c|}{$\begin{array}{l}\text { Mean Difference } \\
\text { IV, Random, } 95 \% \mathrm{CI}\end{array}$}} \\
\hline & \multirow[t]{2}{*}{ Mean } & \multirow[t]{2}{*}{ SD } & \multirow[t]{2}{*}{ Total } & \multirow[t]{2}{*}{ Mean } & \multirow[t]{2}{*}{ SD } & \multirow[t]{2}{*}{ Total } & & & & \\
\hline & & & & & & & ingenting & (n) & & \multirow{4}{*}{-} \\
\hline Suzuki 2004 & 4.3 & 0.7 & 18 & 2.8 & 0.4 & 16 & $30.6 \%$ & $1.50[1.12,1.88]$ & & \\
\hline Wang 2005 & 3.88 & 2.55 & 19 & 2.57 & 2.88 & 13 & $5.2 \%$ & $1.31[-0.63,3.25]$ & & \\
\hline $\begin{array}{l}\text { Zhong } 2007 \\
\text { Subtotal }(95 \% \mathrm{Cl})\end{array}$ & 1.68 & 0.86 & $\begin{array}{l}24 \\
61\end{array}$ & 1.04 & 0.66 & $\begin{array}{l}20 \\
49\end{array}$ & $\begin{array}{l}28.3 \% \\
64.0 \%\end{array}$ & $\begin{array}{l}0.64[0.19,1.09] \\
1.11[0.38,1.83]\end{array}$ & & \\
\hline \multicolumn{11}{|c|}{$\begin{array}{l}\text { Heterogeneity: } \text { Tau }^{2}=0.26 ; \mathrm{Chi}^{2}=8.26, \mathrm{df}=2(P=0.02) ; \mathrm{I}^{2}=76 \% \\
\text { Test for overall effect: } Z=2.99(P=0.003)\end{array}$} \\
\hline \multicolumn{11}{|l|}{ 1.1.2 ACEI } \\
\hline $\begin{array}{l}\text { Li } 2003 \\
\text { Subtotal }(95 \% \mathrm{Cl})\end{array}$ & 1.41 & 0.35 & $\begin{array}{l}26 \\
26\end{array}$ & 0.69 & 0.31 & $\begin{array}{l}27 \\
27\end{array}$ & $\begin{array}{l}36.0 \% \\
36.0 \%\end{array}$ & $\begin{array}{c}0.72[0.54,0.90] \\
0.72[0.54,0.90]\end{array}$ & & 눈 \\
\hline \multicolumn{11}{|c|}{$\begin{array}{l}\text { Heterogeneity: Not applicable } \\
\text { Test for overall effect: } Z=7.92(P<0.00001)\end{array}$} \\
\hline Total $(95 \% \mathrm{Cl})$ & & & 87 & & & 76 & $100.0 \%$ & $0.97[0.49,1.44]$ & & \\
\hline \multicolumn{9}{|c|}{$\begin{array}{l}\text { Heterogeneity: } \mathrm{Tau}^{2}=0.15 ; \mathrm{Chi}^{2}=14.43, \mathrm{df}=3(\mathrm{P}=0.002) ; \mathrm{I}^{2}=79 \% \\
\text { Test for overall effect: } Z=4.00(P<0.0001) \\
\text { Test for subgroup differences: } \mathrm{Chi}^{2}=1.03, \mathrm{df}=1(\mathrm{P}=0.31) . \mathrm{I}^{2}=2.5 \%\end{array}$} & Favors Other Drugs & Favors ${ }^{2}$ ACEI or ARB \\
\hline
\end{tabular}

\section{SR1.2.}

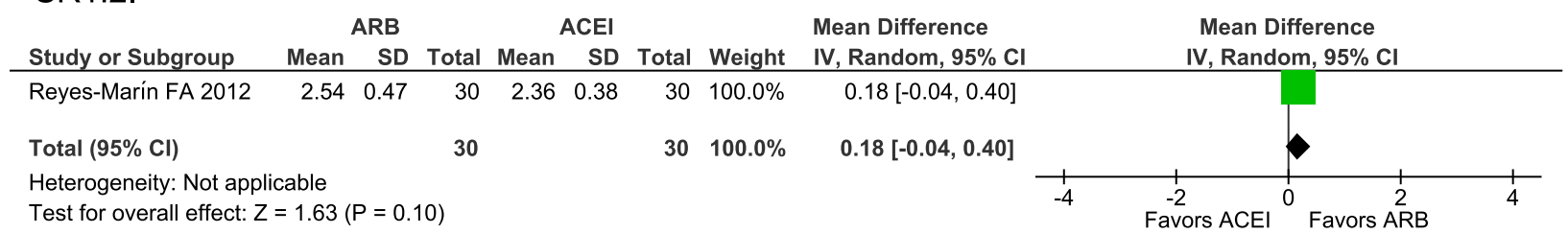

Fig. 2 Comparison of RASIs and other antihypertensive drugs on GFR (SR1.1.). Comparison of ARBs and ACEls on GFR (SR1.2.). RASI, renin-angiotensin system inhibitor; ARB, angiotensin receptor blocker; ACEl, angiotensin-converting enzyme inhibitor; GFR, glomerular filtration rate; SD, standard deviation, $\mathrm{Cl}$, confidence intervals 
Urine volume

\section{SR1.1.}

Five studies reported the efficacies of ARBs versus other antihypertensive drugs on urine volume change after follow-up periods of over 6 months. One study compared two ARBs (Candesartan and Valsartan) and controls [19]. Therefore, we deemed that the study involved two comparisons (Shigenaga 2009 and Shigenaga 2009b) and included the data as two independent studies. ARBs significantly prevented the reduction in urine volume with extensive heterogeneity (MD $142 \mathrm{~mL}, 95 \%$ CI 25.42$259.69, I^{2}=80 \%$ ) (Fig. 3). There were no data about the urine volume change in the study comparing ACEIs and other drugs.

\section{SR1.2.}

One study reported no significant difference in urine volume change between ARBs and ACEIs over 12 months (MD 145.0 mL, 95\% CI - 8.35 to 298.35) (Fig. 3).

\section{Anuria}

SR1.1.

Three studies (ARB, 2; ACEI, 1) indicated no significant difference in the risk ratio of the complete anuria progression rate between patients treated with RASIs and those treated with other antihypertensive drugs after follow-up periods greater than 12 months (RR 0.70, 95\% CI 0.48-1.02, $I^{2}=0 \%$ ) (Fig. 4). In subgroup analysis, there was no significant difference in the risk ratio of the anuria progression rate in the studies comparing $\mathrm{ARBs}$ and other antihypertensive drugs (RR 0.91, 95\% CI 0.43-1.94, $\left.I^{2}=0 \%\right)$, though ACEIs showed a significant reduction of the anuria progression rate (RR $0.64,95 \%$ CI $0.41-0.99$ ).

\section{SR1.2.}

The comparison between ARBs and ACEIs in one study showed no significant difference in the risk ratio of the anuria progression rate over twelve months (RR 1.09, 95\% CI 0.57-2.07) (Fig. 4).

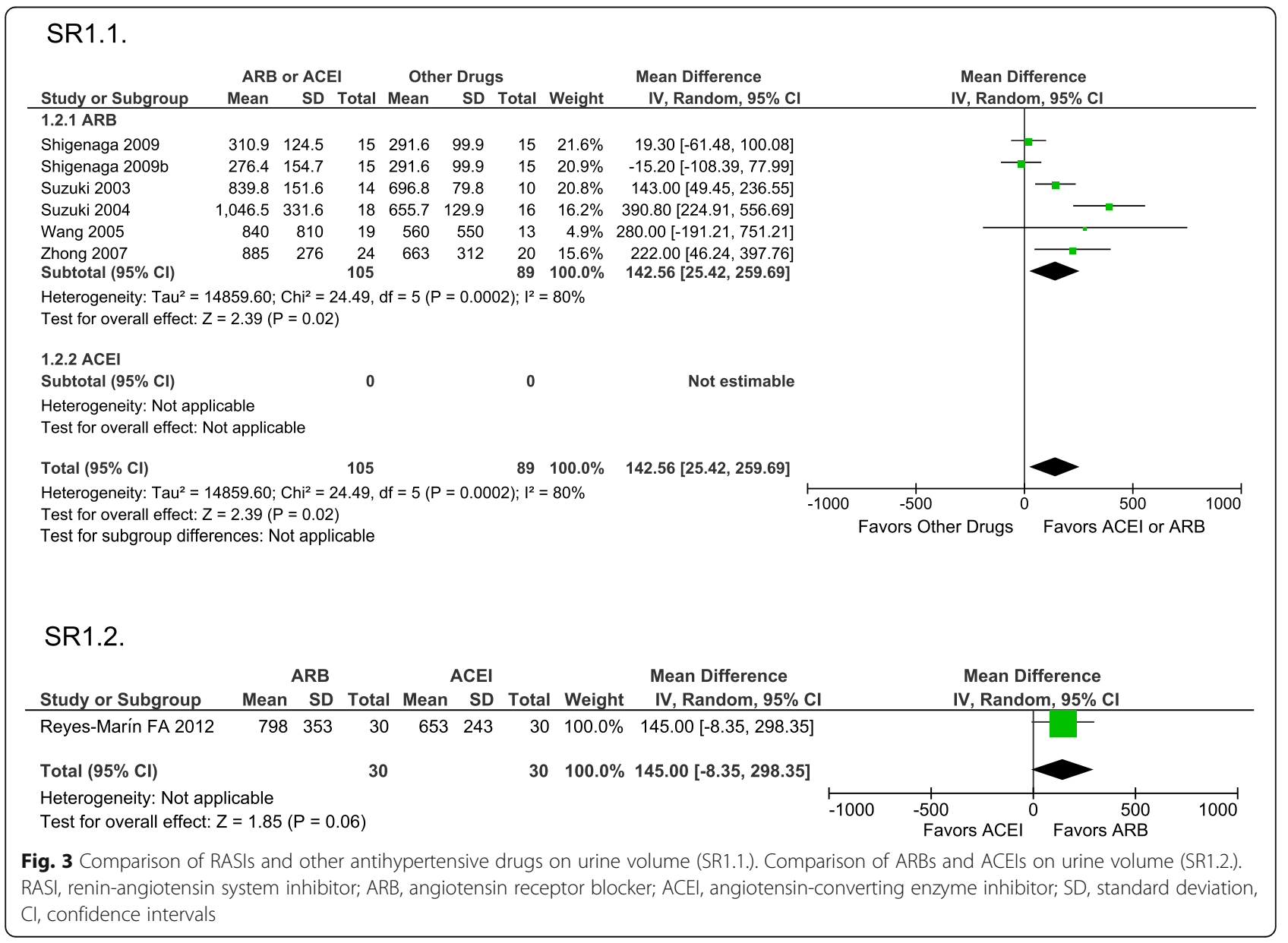




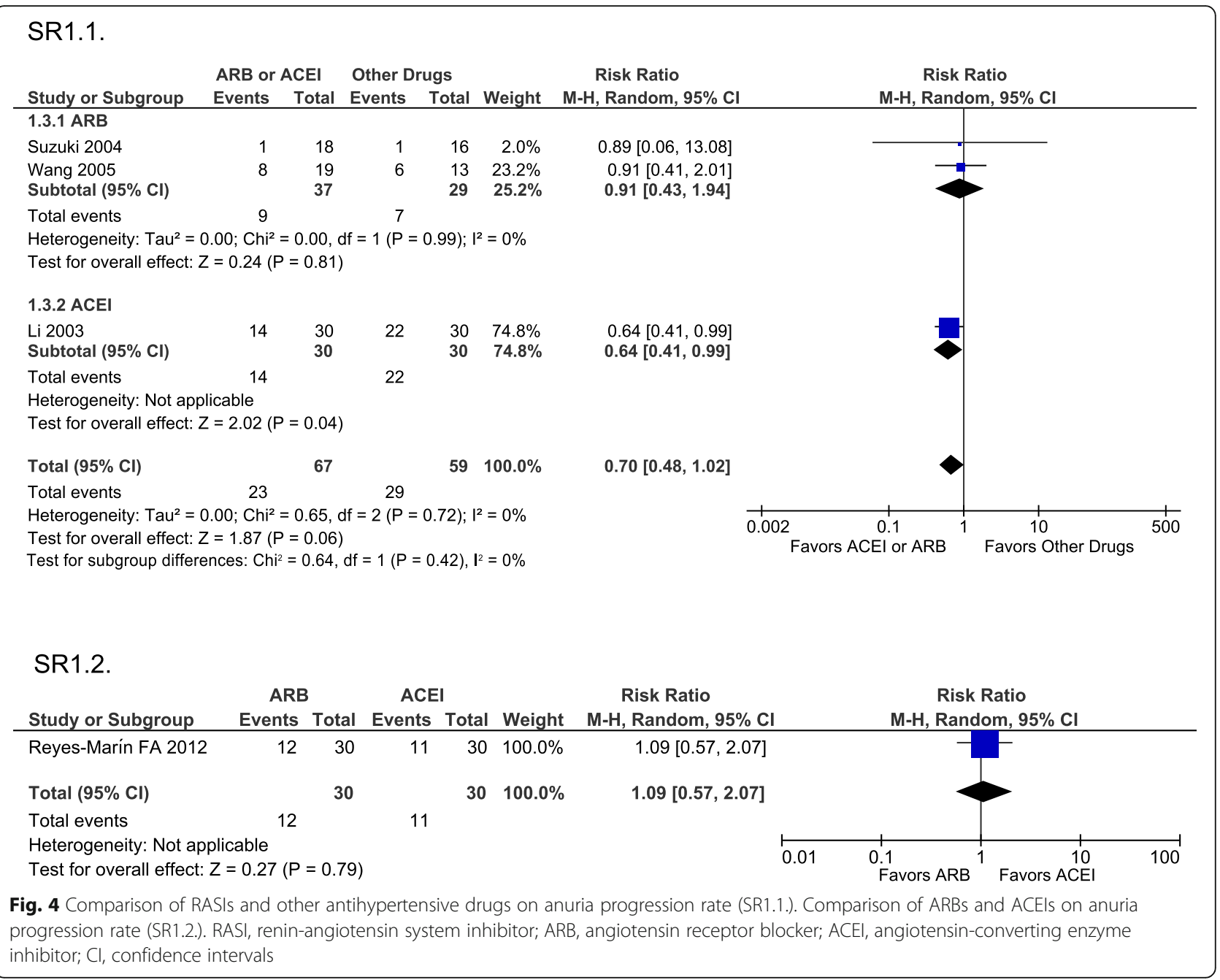

\section{All-cause mortality}

\section{SR1.1.}

We identified the outcome data of all-cause mortality from all six studies (ARB, 5; ACEI, 1). The comparison indicated no significant difference in the risk difference of all-cause mortality between RASIs and other antihypertensive drugs after follow-up periods of over 6 months (RD 0.00, 95\% CI -0.04 to 0.05 , $I^{2}=0 \%$ ) (Fig. 5). The subgroup analysis also showed no significant differences when comparing ARBs and other drugs (RD $0.00,95 \% \mathrm{CI}-0.05$ to $0.05, I^{2}=0 \%$ ), and ACEIs and other drugs (RD 0.03, 95\% CI -0.11 to 0.17$)$.

\section{SR1.2.}

The comparison between ARBs and ACEIs in one study showed no significant difference in the risk difference of all-cause mortality over 12 months (RD 0.00, 95\% CI - 0.06 to 0.06 ) (Fig. 5).

\section{Technical survivals}

SR1.1.

All six studies (ARB, 5; ACEI, 1) were included in the analysis, indicating no significant difference in the risk difference of technical survival between RASIs and other antihypertensive drugs after follow-up periods of over 6 months (RD $-0.00,95 \% \mathrm{CI}-0.05$ to $0.04, I^{2}=0 \%$ ) (Fig. 6). In one study of ARBs [18], the authors mentioned that one participant in the control group transferred to hemodialysis because of ultrafiltration failure; however, the participant was not counted in the final data. Thus, we considered the participant as having a technical failure and added one to the analysis. In another study of ACEIs [10], two participants received kidney transplants and dropped out of the study. We considered them not to be technical failure patients and removed them from the participant tally. The subgroup analysis also showed no significant differences in both comparisons of ARBs and other drugs (RD $-0.01,95 \% \mathrm{CI}-0.06$ to $0.04, I^{2}=0 \%$ ), nor 


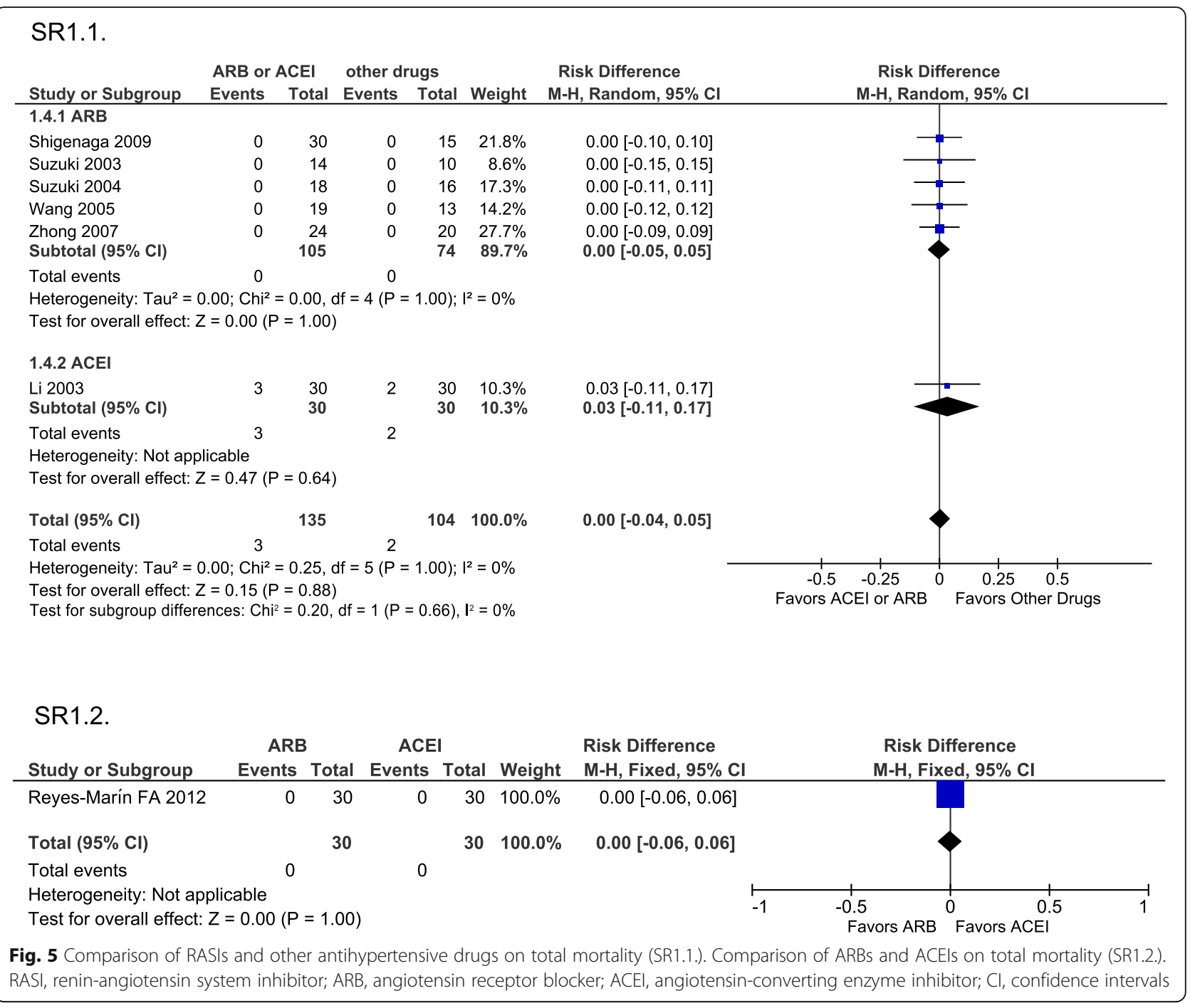

in the comparison of ACEIs and other drugs (RD $0.03,95 \% \mathrm{CI}-0.11$ to 0.18$)$.

\section{SR1.2.}

The comparison between ARBs and ACEIs in one study [20] showed no significant difference in the risk difference of technical survival over 12 months (RD 0.00, 95\% CI -0.06 to 0.06 ) (Fig. 6).

\section{Cardiovascular events}

\section{SR1.1.}

Cardiovascular events were reported in two studies (ARB, 1; ACEI, 1). The comparison showed no significant difference in the risk difference of cardiovascular events between RASIs and other antihypertensive drugs after follow-up periods of over 12 months (RD $0.00,95 \% \mathrm{CI}-0.09$ to $0.09, I^{2}=0 \%$ ) (Fig. 7 ). The subgroup analysis also showed no significant differences in both comparisons of ARBs versus other drugs (RD 0.00, $95 \% \mathrm{CI}-0.11$ to $\left.0.11, I^{2}=0 \%\right)$, nor in the comparison of ACEIs versus other drugs ( $\mathrm{RD} 0.00,95 \% \mathrm{CI}-0.09$ to 0.09).

SR1.2.

The comparison between ARBs and ACEIs in one study showed no significant difference in the risk ratio of a cardiovascular event (RR 1.33, 95\% CI -0.33 to 5.45 ) (Fig. 7).

\section{Hyperkalemia}

SR1.1.

Hyperkalemia was reported in one study comparing two ARBs and other antihypertensive drugs and showed no significant difference in the risk of hyperkalemia over 6 months (RD 0.00, 95\% CI -0.10 to 0.10 ) (Fig. 8). 


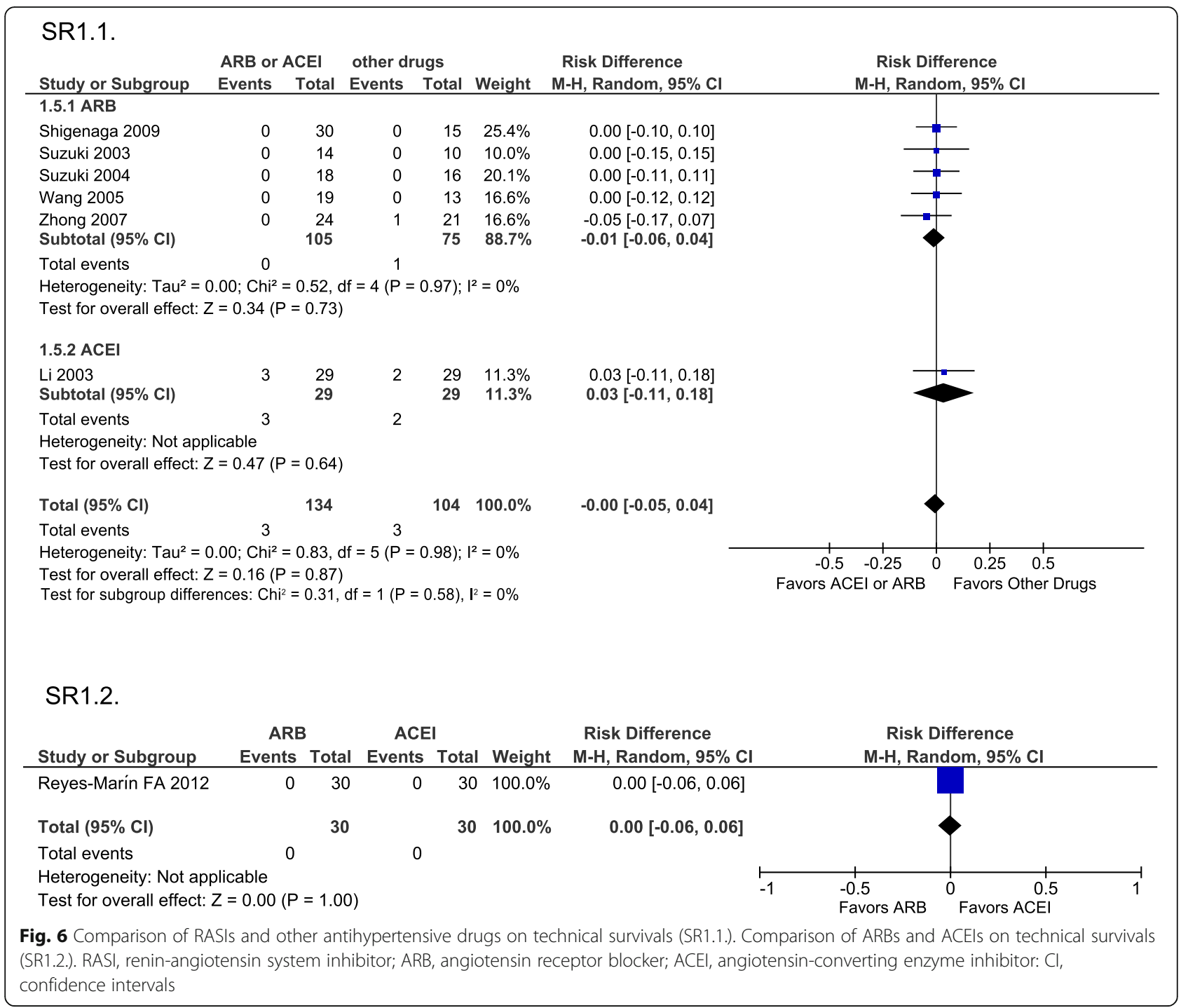

\section{SR1.2.}

The comparison between ARBs and ACEIs in two studies showed no significant difference in the risk difference of hyperkalemia after follow-up periods of over 4 months (RD $0.00,95 \%$ CI -0.06 to $0.06, I^{2}=0 \%$ ) (Fig. 8 ).

\section{Discussion}

In this systematic review, we evaluated eight RCTs and 320 participants. Five studies compared ARBs with other antihypertensive drugs [11, 15, 17-19], and one assessed two ARBs and control drugs [19]. One study compared ACEIs with other antihypertensive drugs [10]. Two studies, one of which was a cross-over RCT [16], compared ARBs with ACEIs [16, 20]. Some meta-analysis in this report was performed combining studies with different follow-up periods, although we considered these variations to be clinically acceptable.
RASIs appeared to preserve RRF in GFR (MD 0.97 $\mathrm{mL} / \mathrm{min} / 1.73 \mathrm{~m}^{2}, 95 \% \mathrm{CI} 0.49-1.44$ ) and urine volume (MD $142.56 \mathrm{ml}, 95 \%$ CI 25.42-259.69), while there were no beneficial effects of RASIs on total mortality, technical survival, cardiovascular events, and anuria progression rate. RASIs did not increase the risk of hyperkalemia as a harmful effect of intervention for PD patients, although hyperkalemia is the decisive reason for which physicians decide to stop RASIs for CKD patients. However, the meta-analysis of urine volume included the RCTs comparing only ARBs and other drugs, without RCTs comparing ACEIs and other drugs. Only ACEIs showed a beneficial effect (RR 0.64, 95\% CI 0.410.99 ) in a subgroup analysis of the anuria progression rate, indirectly suggesting a difference in drug effects between ARBs and ACEIs. However, the direct comparison of ACEIs with ARBs revealed no superiority in either RASI drug in any outcome. In the analysis of GFR and 


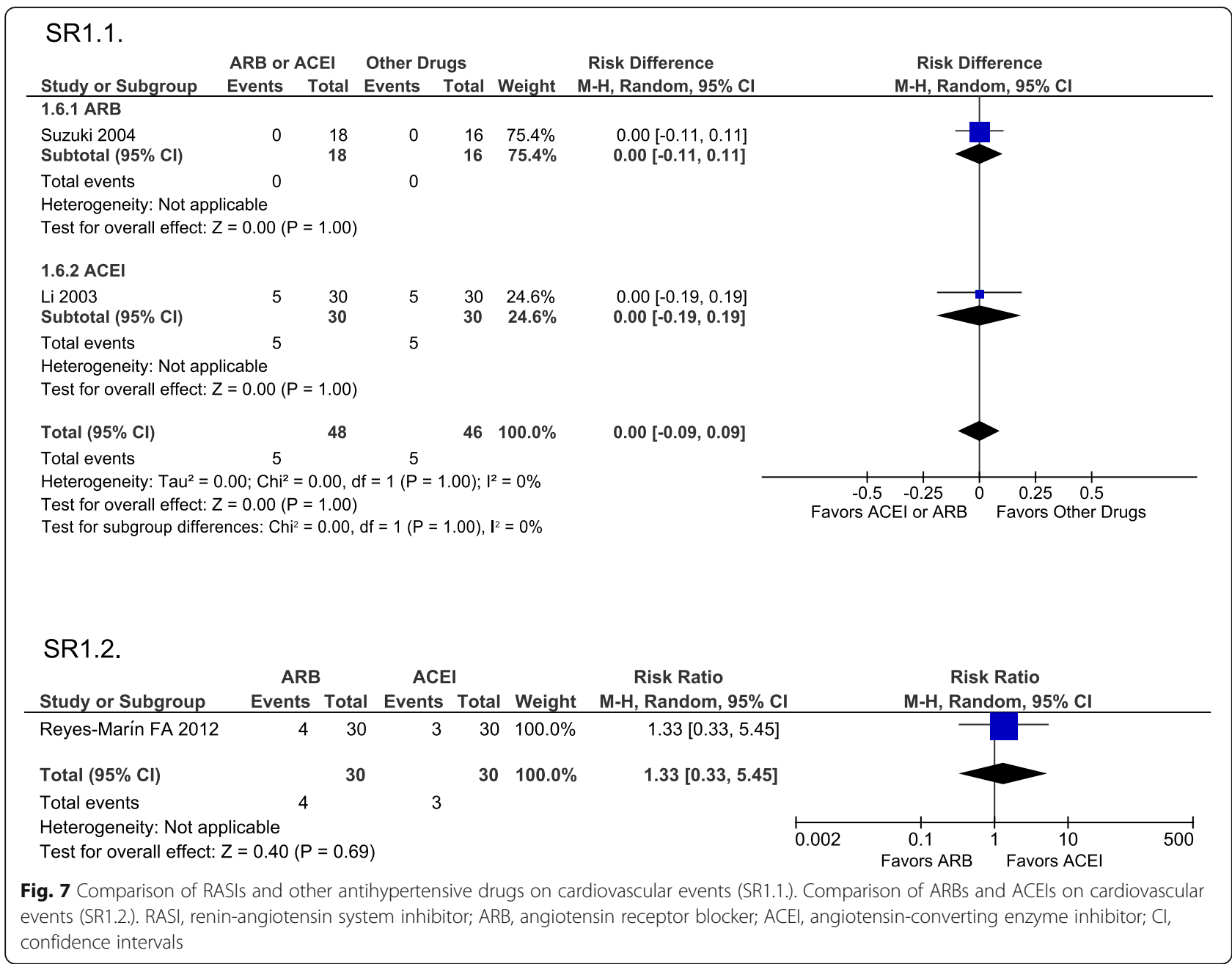

urine volume, we identified a substantial heterogeneity $\left(I^{2}=79 \%, p=0.002\right.$ and $I^{2}=80 \%, p=0.02$, respectively $)$. However, the point estimates in both analyses overlapped or indicated the same tendency in treatment effects (Figs. 2 and 3). Therefore, we considered that the heterogeneities were not clinical. Further detailed subgroup analysis was not possible due to the small number of studies identified.

Most nephrologists prescribe ACEIs and ARBs to preserve renal function in early-stage CKD patients [28]. Several meta-analyses [8, 29] and RCTs [7, 30-35] have reported that ACEIs and ARBs have beneficial effects on the total mortality and the progression to ESKD regardless of the CKD stage and the presence of diabetes. However, recent studies $[36,37]$ revealed that increased creatinine or decreased GFR after the initiation of RASIs correlated with worse renal outcome in predialysis CKD patients. Another study reported that discontinuation of RASIs delayed the progression to ESKD in advanced CKD patients [38]. These opposing effects of RASIs on predialysis patients make it difficult to determine whether RASIs have renoprotective effects in patients undergoing PD. Nevertheless, we identified a clear renoprotective effect of RASIs in PD patients. The mechanisms underlying the renoprotective impact of RASIs for PD patients are multiple and complex and could involve renal hemodynamic factors [39] and histochemical factors [40-42]. The two studies [11, 19] included in this SR showed cardioprotective effects of RASI in PD patients, which might contribute to the mechanism protecting renal function. Furthermore, these results might be due to the synergistic effects of RASI together with PD.

Our results agree with those of previous reported SRs $[25,26]$ that demonstrated the renoprotective effects of RASIs in PD patients. RCTs included in previous SRs overlapped with those in our SR. The previous SRs used GFR and anuria progression rates to assess the renoprotective effects of RASIs, though our study evaluated RRF using urine volume in addition to the above. We therefore included two RCTs into our SR, which assessed 


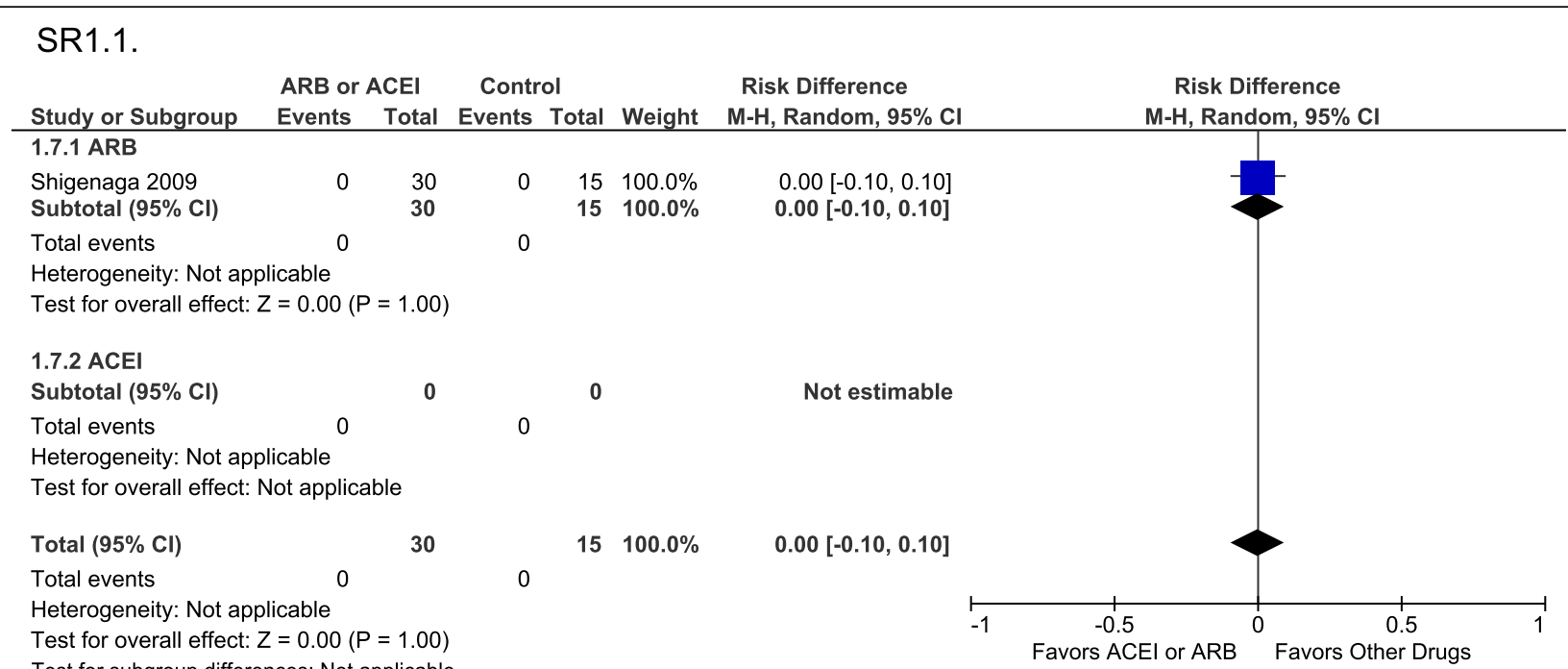

SR1.2.

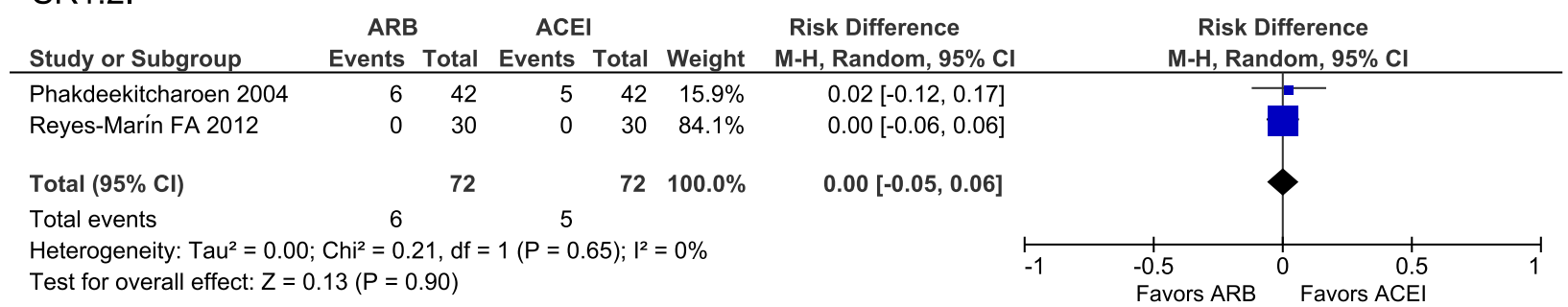

Fig. 8 Comparison of RASIs and other antihypertensive drugs on hyperkalemia (SR1.1.). Comparison of ARBs and ACEls on hyperkalemia (SR1.2.). RASI, renin-angiotensin system inhibitor; ARB, angiotensin receptor blocker; ACEl, angiotensin-converting enzyme inhibitor; Cl, confidence intervals

urine volume as an outcome representing RRF. Urine volume is one of the vital parameters by which patients can be aware of maintaining their renal function.

Several observational studies evaluated the renoprotective effects of RASIs for PD patients which, other than the RCTs included in our SR, showed contradictory results. A retrospective study from Hong Kong reported that the rate of decline of residual GFR was slower in patients who received ACEIs or ARBs [12]. However, three sizeable cohort studies from the US A and the Netherlands concluded that RASIs had no renoprotective benefits for PD patients $[13,14,21]$. The reason for the discrepancy between our findings and the trials showing no benefits of RASIs is complicated. The RCTs included in our SR had stricter patient selection criteria than the observational studies, meaning that patients' background characteristics in the RCTs and the observational studies were considerably different. Therefore, the beneficial effects of RASIs on PD patients might vary according to the patients' individual conditions.

This study has several limitations. First, the number of eligible studies investigating the effect of RASIs in PD patients was very small as we limited them to RCTs. Second, most of the outcomes were not assessed in a blinded manner. Consequently, outcomes such as mortality and technical survival might be affected by performance and detection bias, although residual renal function and urine volume might not be affected. Several past studies [2-6] indicated that preserved residual renal function or urine volume were surrogate markers of hard outcomes such as mortality or technical survival. However, the extent by which residual renal function or urine volume improves these outcomes is unclear. Third, heterogeneity of observation period, type of medicine, and patient background exist between each RCT. Finally, ACEI has different pharmacologic actions than ARB. Although this study showed no difference in primary outcomes between ACEIs and ARBs, only one RCT was eligible for most of the outcomes. Therefore, the possibility of there being different conclusions cannot be excluded. To resolve the abovementioned limitations, more extensive studies, including cohort studies, are warranted. 


\section{Conclusion}

Our analysis revealed that RASIs contribute to preserving GFR and urine volume in PD patients. As the number of study participants was small, further studies with a larger sample size are required.

\section{Supplementary information}

Supplementary information accompanies this paper at (https://doi.org/10. 1186/s41100-019-0238-3).

Additional file 1: Search strategy.

Additional file 2: Summary of findings for ARB or ACEI versus conventional therapy (SR1.1.) in PD patients.

Additional file 3: Summary of findings for ARB versus ACEI (SR1.2.) in PD patients.

\section{Abbreviations}

ACEl: Angiotensin-converting enzyme inhibitor; ARB: Angiotensin receptor blocker; Cl: Confidence interval; CKD: Chronic kidney disease; CPGs: Clinical practice guidelines; ESKD: End-stage kidney disease; GFR: Glomerular filtration rate; HD: Hemodialysis; MD: Mean difference; PD: Peritoneal dialysis; PRISMA: Preferred Reporting Items for Systematic Review and Meta-Analyses; PROSPERO: International Prospective Register of Systematic Reviews; RAS: Renin-angiotensin system; RASI: Renin-angiotensin system inhibitor; RCT: Randomized controlled trials; RD: Risk difference; RR: Risk ratio; RRF: Residual renal function; SR: Systematic review

\section{Acknowledgments}

We thank Shinichi Abe, Mieko Mitani, and Chihiro Ishihara, librarians of the Japan Medical Library Association Expert Searching Working Group for Clinical Practice Guidelines, for advice on the search strategies. We would like to thank Editage (www.editage.com) for English language editing.

\section{Authors' contributions}

$\mathrm{MI}, \mathrm{YS}, \mathrm{YK}, \mathrm{KY}, \mathrm{MR}, \mathrm{YI}$, and $\mathrm{HY}$ contributed to the research idea and study design. MI, YS, YK, and KY contributed to the data acquisition and the quality assessment of the risk of bias. MI, YS, and HY contributed to the data analysis/interpretation. HT, YT, and HY contributed to the supervision in all steps of the systematic review. MI and YS wrote the first draft of the manuscript. All authors interpreted the data analysis and critically revised the manuscript.

\section{Funding}

There is no funding for this study. This systematic review is part of a clinical practice guideline revising project by the Japanese Society of Dialysis Therapy (JSDT).

The JSDT provided for all the endeavors and costs for the systematic review.

\section{Availability of data and materials}

All datasets analyzed in this systematic review are referenced in the manuscript.

\section{Ethics approval and consent to participate}

Not applicable

\section{Consent for publication}

Not applicable

\section{Competing interests}

The authors declare that they have no competing interests.

\section{Author details}

${ }^{1}$ Working Group on Revision of Peritoneal Dialysis Guidelines, Japanese Society of Dialysis Therapy, Tokyo, Japan. ${ }^{2}$ Department of Nephrology and Dialysis Center, Yabuki Hospital, 4-5-5 Shima-Kita, Yamagata 990-2464, Japan. ${ }^{3}$ Department of Nephrology, Kasugai Municipal Hospital, Kasugai, Aichi, Japan. ${ }^{4}$ Department of Nephrology, Japanese Red Cross Fukuoka Hospital,
Fukuoka, Japan. ${ }^{5}$ Department of Nephrology, Masuko Memorial Hospital, Nagoya, Aichi, Japan.

Received: 27 June 2019 Accepted: 3 September 2019

Published online: 14 September 2019

\section{References}

1. Bargman JM, Thorpe KE, Churchill DN. Relative contribution of residual renal function and peritoneal clearance to adequacy of dialysis: a reanalysis of the CANUSA study. J Am Soc Nephrol. 2001;12:2158-62.

2. Paniagua $R$, Amato D, Vonesh E, Correa-Rotter R, Ramos A, Moran J, et al. Effects of increased peritoneal clearances on mortality rates in peritoneal dialysis: ADEMEX, a prospective, randomized, controlled trial. J Am Soc Nephrol. 2002;13:1307-20.

3. Termorshuizen F, Korevaar JC, Dekker FW, Van Manen JG, Boeschoten EW, Krediet RT. The relative importance of residual renal function compared with peritoneal clearance for patient survival and quality of life: an analysis of the Netherlands Cooperative Study on the Adequacy of Dialysis (NECOSAD)-2. AJKD. 2003;41:1293-302.

4. Marrón B, Remón C, Pérez-Fontán M, Quirós P, Ortíz A. Benefits of preserving residual renal function in peritoneal dialysis. Kidney Int. 2008;73: S42-51.

5. Maiorca R, Brunori G, Zubani R, Cancarini GC, Manili L, Camerini C, et al. Predictive value of dialysis adequacy and nutritional indices for mortality and morbidity in CAPD and HD patients. A longitudinal study. Nephrol Dial Transplant. 1995:10:2295-305.

6. Davies SJ, Phillips L, Russell Gl. Peritoneal solute transport predicts survival on CAPD independently of residual renal function. Nephrol Dial Transplant. 1998;13:962-8.

7. Hsu TW, Liu JS, Hung SC, Kuo KL, Chang YK, Chen YC, et al. Renoprotective effect of renin-angiotensin-aldosterone system blockade in patients with predialysis advanced chronic kidney disease, hypertension,and anemia. JAMA Intern Med. 2014;174:347-54

8. Xie X, Liu Y, Perkovic V, Li X, Ninomiya T, Hou W, et al. Renin-angiotensin system inhibitors and kidney and cardiovascular outcomes in patients with CKD: a bayesian network meta-analysis of randomized clinical trials. Am J Kidney Dis. 2016;67:728-41.

9. Japanese Society of Nephrology. Essential points from evidence-based clinical practice guidelines for chronic kidney disease 2018. Clin Exp Nephrol. 2019;23:1-15

10. Li PK-T, Chow K-M, Wong TY-H, Leung C-B, Szeto C-C. Effects of an angiotensin-converting enzyme inhibitor on residual renal function in patients receiving peritoneal dialysis. A randomized, controlled study. Ann Intern Med. 2003;139:105-12

11. Suzuki $H$, Nakamoto $H$, Okada $H$, Sugahara $S$, Kanno $Y$. A selective angiotensin receptor antagonist, Valsartan, produced regression of left ventricular hypertrophy associated with a reduction of arterial stiffness. Adv Perit Dial. 2003:19:59-66.

12. Szeto C-C, Kwan BC-H, Chow K-M, Chung S, Yu V, Cheng PM-S, et al. Predictors of residual renal function decline in patients undergoing continuous ambulatory peritoneal dialysis. Perit Dial Int. 2015;35:180-8.

13. Shen Jl, Saxena AB, Montez-Rath ME, Chang TI, Winkelmayer WC Angiotensin-converting enzyme inhibitor/angiotensin receptor blocker use and cardiovascular outcomes in patients initiating peritoneal dialysis. Nephrol Dial Transplant. 2017;32:862-9.

14. Shen Jl, Saxena AB, Vangala S, Dhaliwal SK, Winkelmayer WC. Reninangiotensin system blockers and residual kidney function loss in patients initiating peritoneal dialysis: an observational cohort study. BMC Nephrol. 2017;18:1-10

15. Suzuki H, Kanno Y, Sugahara S, Okada H, Nakamoto H. Effects of an angiotensin II receptor blocker, Valsartan, on residual renal function in patients on CAPD. Am J Kidney Dis. 2004;43:1056-64.

16. Phakdeekitcharoen B, Leelasa-nguan P. Effects of an ACE inhibitor or angiotensin receptor blocker on potassium in CAPD patients. Am J Kidney Dis. 2004:44:738-46.

17. Wang J, Xiao MY. Protective effects of Valsartan on residual renal function in patients on CAPD. Chinese J Blood Purif. 2005:4:605-7.

18. Zhong H, Sha Z-H, Cui T-L, Qiu H-Y, Liu F, Qin W, Fu P. Effects of Irbesartan on residual renal function in peritoneal dialysis patients. Chinese J Nephrol. 2007;23:413-7. 
19. Shigenaga A, Tamura K, Dejima T, Ozawa M, Wakui H, Masuda S, et al. Effects of angiotensin II type 1 receptor blocker on blood pressure variability and cardiovascular remodeling in hypertensive patients on chronic peritoneal dialysis. Nephron. 2009;112:c31-40.

20. Reyes-Marín FA, Calzada C, Ballesteros A, Amato D. Comparative study of enalapril vs. losartan on residual renal function preservation in automated peritoneal dialysis. A randomized controlled study. Rev Investig. Clin. 2012; 64:315-21.

21. Kolesnyk I, Noordzij M, Dekker FW, Boeschoten EW, Krediet RT. Treatment with angiotensin II inhibitors and residual renal function in peritoneal dialysis patients. Perit Dial Int. 2011;31:53-9.

22. Atabak S, Taziki O, Argani H, Abolghasemi R. Effects of oral enalapril and verapamil on dialysis adequacy and solute clearance in chronic ambulatory peritoneal dialysis. Saudi J Kidney Dis Transplant. 2013;24:1170-4.

23. Moher D, Liberati A, Tetzlaff J, Altman DG, Altman D, Antes G, et al. Preferred reporting items for systematic reviews and meta-analyses: the PRISMA statement. PLoS Med. 2009;6.

24. Julian PT, Higgins SG. Cochrane Handbook for Systematic Reviews of Interventions Version 5.1.0. https://training.cochrane.org/handbook. Accessed 24 April 2017.

25. Akbari A, Knoll G, Ferguson D, McCormick B, Davis A, Biyani M. Angiotensinconverting enzyme inhibitors and angiotensin receptor blockers in peritoneal dialysis: systematic review and meta-analysis of randomized controlled trials. Perit Dial Int. 2009;29:554-61.

26. Zhang L, Zeng X, Fu P. Wu HM. Angiotensin-converting enzyme inhibitors and angiotensin receptor blockers for preserving residual kidney function in peritoneal dialysis patients. Cochrane Database Syst Rev. 2014:CD009120.

27. Nakamoto H, Kanno Y, Okada H, Suzuki H. Erythropoietin resistance in patients on continuous ambulatory peritoneal dialysis. Adv Perit Dial. 2004;20:111-6.

28. Mangrum AJ, Bakris GL. Angiotensin-converting enzyme inhibitors and angiotensin receptor blockers in chronic renal disease: Safety Issues. Semin Nephrol. 2004;24:168-75.

29. Nistor I, De Sutter J, Drechsler C, Goldsmith D, Soler MJ, Tomson C, et al. Effect of renin-angiotensin-aldosterone system blockade in adults with diabetes mellitus and advanced chronic kidney disease not on dialysis: a systematic review and meta-analysis. Nephrol Dial Transplant. 2018;33:12-22.

30. Brenner BM, Cooper ME, de Zeeuw D, Keane WF, Mitch WE, Parving H-H, et al. Effects of losartan on renal and cardiovascular outcomes in patients with type 2 diabetes and nephropathy. N Engl J Med. 2001;345:861-9.

31. Kurokawa K, Chan JCN, Cooper ME, Keane WF, Shahinfar S, Zhang Z. Renin angiotensin aldosterone system blockade and renal disease in patients with type 2 diabetes: a subanalysis of Japanese patients from the RENAAL study. Clin Exp Nephrol. 2006;10:193-200.

32. Lewis $E$, Hunsicker $L$, Raz I. Renoprotective effect of the angiotensinreceptor antagonist. N Engl J Med. 2001;345:851-60.

33. Agodoa LY, Appel L, Bakris GL, Beck G, Bourgoignie J, Briggs JP, et al. Effect of ramipril vs amlodipine on renal outcomes in hypertensive nephrosclerosis: a randomized controlled trial. JAMA. 2001;285:2719-28.

34. Kent DM, Jafar TH, Hayward RA, Tighiouart H, Landa M, de Jong P, et al. Progression risk, urinary protein excretion, and treatment effects of angiotensin-converting enzyme inhibitors in nondiabetic kidney disease. J Am Soc Nephrol. 2007;18:1959-65.

35. Hou FF, Zhang X, Zhang GH, Xie D, Chen PY, Zhang WR, et al. Efficacy and safety of benazepril for advanced chronic renal insufficiency. N Engl J Med. 2006;354:131-40.

36. Clase CM, Barzilay J, Gao P, Smyth A, Schmieder RE, Tobe S, et al. Acute change in glomerular filtration rate with inhibition of the renin-angiotensin system does not predict subsequent renal and cardiovascular outcomes. Kidney Int. 2017;91:683-90.

37. Schmidt M, Mansfield KE, Bhaskaran K, Nitsch D, Sørensen HT, Smeeth L, et al. Serum creatinine elevation after renin-angiotensin system blockade and long term cardiorenal risks: cohort study. BMJ. 2017;356:j791.

38. Ahmed AK, Kamath NS, El Kossi M, El Nahas AM. The impact of stopping inhibitors of the renin-angiotensin system in patients with advanced chronic kidney disease. Nephrol Dial Transplant. 2010;25:3977-82.

39. Zatz R, Dunn BR, Meyer TW, Anderson S, Rennke HG, Brenner BM. Prevention of diabetic glomerulopathy by pharmacological amelioration of glomerular capillary hypertension. J Clin Invest. 1986;77:1925-30.

40. Wolf G, Haberstroh U, Neilson EG. Angiotensin II stimulates the proliferation and biosynthesis of type I collagen in cultured murine mesangial cells. Am J Pathol. 1992;140:95-107.
41. Kagami S, Border WA, Miller DE, Noble NA. Angiotensin II stimulates extracellular matrix protein synthesis through induction of transforming growth factor-beta expression in rat glomerular mesangial cells. J Clin Invest. 1994;93:2431-7.

42. Fogo $A B$. The role of angiotensin II and plasminogen activator inhibitor-1 in progressive glomerulosclerosis. Am J Kidney Dis. 2000;35:179-88.

\section{Publisher's Note}

Springer Nature remains neutral with regard to jurisdictional claims in published maps and institutional affiliations.
Ready to submit your research? Choose BMC and benefit from:

- fast, convenient online submission

- thorough peer review by experienced researchers in your field

- rapid publication on acceptance

- support for research data, including large and complex data types

- gold Open Access which fosters wider collaboration and increased citations

- maximum visibility for your research: over $100 \mathrm{M}$ website views per year

At BMC, research is always in progress.

Learn more biomedcentral.com/submissions 